\title{
Author Correction: Temporal dynamic reorganization of 3D chromatin architecture in hormone-induced breast cancer and endocrine resistance
}

\author{
Yufan Zhou, Diana L. Gerrard, Junbai Wang (1), Tian Li, Yini Yang, Andrew J. Fritz, Mahitha Rajendran, \\ Xiaoyong Fu, Gary Stein, Rachel Schiff, Shili Lin, Seth Frietze (i) \& Victor X. Jin
}

Correction to: Nature Communications https://doi.org/10.1038/s41467-019-09320-9, published online 03 April 2019.

The original version of this Article omitted from the author list the 9th author 'Gary Stein', who is from the 'Department of Biochemistry, University of Vermont Larner College of Medicine'. Consequently, the following was added to the Author Contributions: 'Y.Z. performed the data analysis. V.X.J., Y.Z. and S.F. wrote the manuscript, with all authors including J.W., M.R., X.F., G.S., R.S. and S.L. contributing to writing and providing the feedback.' This has been corrected in both the PDF and HTML versions of the Article.

Published online: 20 April 2020

\footnotetext{
(c) (i) Open Access This article is licensed under a Creative Commons Attribution 4.0 International License, which permits use, sharing, adaptation, distribution and reproduction in any medium or format, as long as you give appropriate credit to the original author(s) and the source, provide a link to the Creative Commons license, and indicate if changes were made. The images or other third party material in this article are included in the article's Creative Commons license, unless indicated otherwise in a credit line to the material. If material is not included in the article's Creative Commons license and your intended use is not permitted by statutory regulation or exceeds the permitted use, you will need to obtain permission directly from the copyright holder. To view a copy of this license, visit http://creativecommons.org/licenses/by/4.0/.
}

(C) The Author(s) 2020 